\title{
Analysis of the Carbothermic Reduction of Iron Ore-Coke Composite Mixtures by Microwave Heating
}

\author{
Giulio Antunes de Medeiros ${ }^{a}$, Leonardo Martins da Silva ${ }^{a *}$ (D), Márcio Teodoro Fernandes ${ }^{a, b}$, \\ Daniel Gomes de Souza dos Santos ${ }^{\text {, José Adilson de Castro }}{ }^{a}$ \\ ${ }^{a}$ Universidade Federal Fluminense, Avenida dos Trabalhadores, 420, Vila Sta. Cecília, 27255-125, \\ Volta Redonda, RJ, Brasil. \\ ${ }^{b}$ Faculdade Sul Fluminense, Rua Alberto Cunha Rodrigues, 39, Jardim Amália, 27251-220, \\ Volta Redonda, RJ, Brasil.
}

Received: June 14, 2021; Revised: August 24, 2021; Accepted: September 05, 2021

\begin{abstract}
In recent decades, microwave energy has been successfully experimented for mining and metallurgy processes and is considered a promising new method for ironmaking. In this context, in the present work, self-reducing mixtures composed of fines of iron ore and coke were prepared, intending to evaluate the degree of reduction of iron ore using microwave energy, applying different contents of coke, levels of power, and reaction times. For this, the degree of reduction was assessed as a function of these variables. Additionally, the reduction kinetics was investigated using chemical and diffusional models, and the microstructure of the samples was evaluated using scanning electron microscopy (SEM). The highest degree of reduction obtained after the experiments was greater than $60 \%$ and a statistical investigation showed that the reaction time is the factor with the greatest influence on these results, followed by microwave power and coke content. The investigation of the reaction kinetics showed that the process is chemically controlled, depending on the gasification steps governed by the Boudouard reaction. The images obtained by SEM led to the conclusion that the temperature inside the sample reached $1200^{\circ} \mathrm{C}$. Pig iron was found both in the form of whiskers and in the form of metallic droplets.
\end{abstract}

Keywords: Microwave energy; Iron ore; Self-reduction.

\section{Introduction}

The current blast furnace can be considered the main process for obtaining pig iron and is suitable for mass production of various steel products and high-quality steel. On the other hand, since the blast furnace depends heavily on coal as the main reducer and energy source, its operation is closely related to resources, energy, and environmental issues. In addition, the price of coal and the overall energy situation has a major influence on the cost of steel production.

According to Ariyama et al. ${ }^{1}$ since the end of the 20th century, global warming has been recognized as a critical problem and, as a result, low carbon processes have been pursued in the steel industry. The ironmaking process has a particularly large influence on $\mathrm{CO}_{2}$ emissions due to its high carbon consumption.

In this scenario, an alternative to blast furnace processes emerged as the self-reduction process came up as a variation of direct reduction techniques. These technologies, based on eliminating the need for an external reducing agent, have demonstrated considerable flexibility regarding the possibility of recycling waste such as dust from steelmaking processes.

Another promising advance for the reduction of iron oxides contained in the ore is the application of microwave energy as a heating source for self-reduction. Studies carried out $^{2-5}$ state that microwave heating is a totally new area of

*e-mail: leonardouffsilva@gmail.com. research in the reduction of iron ores, consisting of a unique approach and therefore differing from conventional heating in many ways.

The fundamental characteristic of the application of microwave heating in these processes is found in the high heating rate and the creation of fractures that enhance the flow of reducing gases during the reduction process, in addition to the radiation heating that is generated from the material core $^{6}$. However, as well as rapid heating and improvement in the flow of gases, there are other inherent advantages of this route using the heating promoted by microwave energy when compared to traditional processes. Such advantages are found in the great environmental benefits, among which the reduction of $\mathrm{CO}_{2}$ during the heating process of the particles ${ }^{7,8}$, since the carbonaceous material inherent to the production of pig iron becomes necessary mainly as a chemical factor and no longer energetic.

This heating process is based on the premise that microwave energy is a non-ionizing electromagnetic radiation with frequencies in the range of $0.3-300 \mathrm{GHz}$, although the $2.45 \mathrm{GHz}$ frequency range is widely used in industries. Microwaves generate molecular movement through the migration of ionic species and the rotation of dipolar species. Microwave heating of material directly depends on the relationship between the dielectric loss and the dielectric constant, also known as the dissipation 
factor $^{9-11}$. Haque et al. ${ }^{9}$ reported an extensive review on the application of microwave energy in mineral treatment processes, which observed that a thermal expansion of the target mineral would occur with specific heating, resulting in the formation of cracks that will allow a better degree of reduction of the ore during heating.

This physical process is described by the complex dielectric constant (permissiveness) as $\varepsilon=\varepsilon_{r}+i \varepsilon_{i}=\varepsilon_{0}\left(k_{r}+i k_{i}\right)$.

$k_{r}$ is considered the real part of the relative permissiveness, $k_{i}$ is the imaginary part and $\varepsilon_{0}$ defines the permissiveness of the vacuum. Microwave absorption is governed mainly by $k_{i}$ and is directly related to the chemical composition of the material, temperature, the frequency of the electric field, etc. ${ }^{12-14}$.

According to Hartilieb et al. ${ }^{15}$ due to the application of microwave irradiation to ore particles, differential thermal stresses around the grain boundaries are intensified and considered the main source of cracking of particles. Analyzes indicated that for mineral particles where strong absorbing minerals are found in a non-absorbent matrix, the minerals of the ore particles heat extraordinarily fast compared to gangue $^{16,17}$. According to these studies, the thermal expansion that occurs due to microwave absorption is greater for the matrix phase and creates tensile stresses around the grain boundaries, with thermal stresses and fractures being observed in iron ore samples submitted to different heating rates by emission of microwave energy.

The application of microwave energy in the steel industry encompasses studies from the treatment of ores ${ }^{18-20}$ and attempts to design a furnace for obtaining pig iron ${ }^{21,22}$ to the recovery of the metallic load from steel residues ${ }^{23}$ and also the treatment and effects of microwave irradiation on blast furnace slag ${ }^{24,25}$. However, the main results come from kinetic tests of carbothermic reduction of iron ore and carbon-rich material mixtures. These are also extensively studied using conventional heating methods such as the $\mathrm{EAF}^{26,27}$.

Standish et al. ${ }^{28,29}$ were the authors of one of the first studies that aimed to obtain pig iron using microwave energy heating, analyzing both the reduction of particles composed mainly of magnetite under a controlled atmosphere of CO and $\mathrm{N}_{2}$ and the reduction of mixtures composed of iron and carbon oxide fines, obtaining results that demonstrated the advantage of applying this type of process.

In another groundbreaking study, Zhong et al. ${ }^{30}$ obtained high metallization by applying microwaves with a power of $15 \mathrm{~kW}$ to pellets composed of coal and magnetite in a relatively short time.

Mourão et al. ${ }^{2}$ contributed to the studies on the use of microwave energy in the ironmaking industry. They carried out comparative experiments relating this type of heating to heating by conventional means applied to self-reducing mixtures composed of iron ore and carbonaceous material in the form of pellets. The authors showed that it is not only possible to obtain reaction temperatures that make it possible to reduce iron oxides through the application of microwave energy, but also that the degree of reduction obtained for the pellets is in line with the results obtained employing heating methods that are already established such as the electric resistance oven.
Later on, Ishizaki et al. ${ }^{3,4}$ conducted studies to obtain pig iron from the reduction by microwave heating of pellets composed of magnetite and coal under an inert $\mathrm{N}_{2}$ atmosphere. The results showed that the iron ore reduction reactions started at around $800^{\circ} \mathrm{C}$ with the production of pig iron in liquid form at around $1350^{\circ} \mathrm{C}$ at specific sites contained within the pellets where a certain heating concentration was observed, also showing a lower level of impurities in pig iron than those obtained in the traditional blast furnace process.

Many authors have largely explored microwave applications to biomass pyrolysis aiming at minerals reduction. Kangqiang et al. ${ }^{31-33}$, for example, conducted research on the kinetic characteristics of walnut shell biomass as the reducing agent for regular and low-grade pyrolusite reduction, providing valuable insight into future industrial implementation.

Other studies that use microwave energy in the carbothermic reduction of iron ores have also proved that it is possible to obtain pig iron under air composition instead of maintaining an inert atmosphere 5 . Other authors ${ }^{34}$ have also shown that it is feasible to recycle wastes such as plastics, which, through their gasification, allow the formation of relevant reducing gases such as $\mathrm{CO}$ and others such as $\mathrm{H}_{2}$ or $\mathrm{CH}_{4}$, which can also provide the reduction of iron oxides ${ }^{35}$ allowing the reduction of iron ores in a homogeneous mixture heated with microwave energy.

Therefore, in this work, the iron ore reduction mechanism is evaluated using microwave energy as a heating source and coke fines as a carbon source. The experiments were planned in order to statistically investigate the effects of reaction time, amount of coke and power applied to the samples, with the latter approach being the differential concerning previous studies on the subject, allowing the assessment of the key variable to the process. Additionally, the microstructure of the samples was investigated and the controlling step of the reduction kinetics was determined using chemical and diffusional models, providing significant knowledge on the mechanisms and reactions involved in the self-reduction phenomena by microwave heating.

\section{Materials and Methods}

\subsection{Characterization of the materials}

Homogeneous self-reducing mixtures were produced from iron ore and coke fines with an average particle size smaller than $53 \mu \mathrm{m}$ previously dried in a drying oven at $110^{\circ} \mathrm{C}$ for 2 hours. The iron ore samples used in this work were submitted to powder and chemically analyzed by X-ray diffraction (XRD) (equipment model D4 Endeavor, by Bruker) using the Rietveld method to identify the phases and chemical species. The X-ray diffraction technique using the Rietveld method is based on the simulation of a complete diffraction profile based on structural parameters of the constituent phases, allowing as much information as possible to be extracted from the diffractograms. The Rietveld method takes into account the overlapping peaks of all the phases present, as well as the contributions of background noise. Diffractograms and qualitative spectral interpretations were performed by comparison with standards contained in a database using Bruker-AXS Diffrac. Eva 4.3 software. 
Cobalt $\mathrm{K} \alpha$ radiation was used, with a wavelength of $1.79 \AA$ and scanning was performed in the range from 4 to $105^{\circ}$, with a goniometer speed of $0.02^{\circ}$ per step with a counting time of 1 second per step. The mineralogical composition of the iron ore samples used in this investigation is displayed in Table 1.

Hematite, Quartz, and Goethite were the main phases identified through the X-ray diffraction method for iron ore, where the absence of apatitic and aluminum-silicate compounds was observed.

Chemical analysis for coke was carried out by proximate analysis following the ASTM D3172-13 ${ }^{36}$ standard for obtaining the fixed carbon, volatile matter, ashes and moisture contents, as presented in Table 2. Moisture content was negligible.

\subsection{Experimental procedures and statistical and physical-chemical analyzes}

For the evaluation of the process of carbothermal reduction of iron ore using microwave energy, a statistical technique known as the Central Composite Rotatable Design (CCRD) was used where it was possible to evaluate the influence of the independent variables time of reaction, power, and amount of coke in the degree of reduction of samples submitted to tests in a microwave reactor. For that, samples of $10 \mathrm{~g}$ were produced, composed of fines of iron ore and coke.

Experimental planning based on statistical principles allows the maximum amount of useful information to be extracted from the system under study, making a minimum number of experiments and constituting one among several techniques available to scientists and engineers to correct and improve systems, processes, and products. These techniques

Table 1. Mineralogical composition of the iron ore sample ( $\%$ by mass fraction).

\begin{tabular}{ccc}
\hline Mineral & Chemical Formula & Mass Fraction (\%) \\
\hline Hematite & $\left(\mathrm{Fe}_{2} \mathrm{O}_{3}\right)$ & 82.0 \\
\hline Kaolinite & {$\left[\mathrm{Al}_{2} \mathrm{Si}_{2} \mathrm{O}_{5}(\mathrm{OH})_{4} \cdot\right]$} & 1.8 \\
\hline Quartz & $\left(\mathrm{SiO}_{2}\right)$ & 9.5 \\
\hline Gibbsite & {$\left[\mathrm{Al}(\mathrm{OH})_{3}\right]$} & 0.3 \\
\hline Goethite & {$[\mathrm{FeO}(\mathrm{OH})]$} & 3.7 \\
\hline Magnetite & $\left(\mathrm{Fe}_{3} \mathrm{O}_{4}\right)$ & 0.9 \\
\hline Maghemite & $\left(\mathrm{Fe}_{2} \mathrm{O}_{3}, \gamma-\mathrm{Fe}_{2} \mathrm{O}_{3}\right)$ & 1.8
\end{tabular}

Table 2. Composition of the coke sample (\% by mass fraction).

\begin{tabular}{cc}
\hline Component & Mass Fraction (\%) \\
\hline Fixed Carbon & 88.44 \\
\hline Volatile Matter & 0.50 \\
\hline Ashes & 11.06 \\
\hline
\end{tabular}

Table 3. Variables and levels used in factorial design.

\begin{tabular}{cccccc}
\hline $\begin{array}{c}\text { Variables/ } \\
\text { Levels }\end{array}$ & -1.68 & -1 & 0 & 1 & 1.68 \\
\hline Time (min) & 1 & 3 & 6 & 9 & 11 \\
\hline Power (\%) & 10 & 30 & 50 & 70 & 100 \\
\hline Coke (\%) & 5 & 10 & 15 & 20 & 25 \\
\hline
\end{tabular}

are powerful tools with which several specific objectives can be achieved ${ }^{37}$.

Table 3 presents the values used in the factorial design within each experimental coefficient interval and within the levels $(-1,+1)$ and outside these levels.

The values shown in Table 3 were stipulated considering the average between the upper and lower axial values.

Using the Thermocalc ${ }^{\circledR}$ software ${ }^{38}$ and in order to ensure significance to the experiment results, phase diagrams relating temperatures and carbon percentage effects were carried out for each of the self-reducing mixtures described in the experimental design. These can be seen in Figures 1A to 1E.

In Figure 1, phase diagrams are presented in which it is observed that for temperature values above $800^{\circ} \mathrm{C}$, there is the formation of pig iron in the form of ferrite and austenite.

Table 4 lists the interactions between independent variables to be analyzed in this study using an experimental design composed of 20 tests.

A conventional microwave reactor (Model: PMS-24) with a power of $1200 \mathrm{~W}$ emitting microwave radiation with a frequency of $2450 \mathrm{MHz}$ was used to treat the samples. In the conventional microwave reactor, microwaves are generated through the equipment called magnetron, whose output is located in the upper right corner of the oven. Therefore, the sample of the self-reducing mixture was placed in the lower left part of the equipment, where it was observed to be the place where there is a higher incidence of microwave radiation. The interior of the reactor had dimensions of $260 \mathrm{~mm}$ (height), $460 \mathrm{~mm}$ (width), and $320.3 \mathrm{~mm}$ (length).

The samples were inserted one at a time into the reactor using a ceramic crucible as the recipient, thermally insulated with refractory brick. They were treated with different levels of time and microwave power under air atmosphere. When the residence time of the sample in the reactor was reached, the treatment was interrupted and the sample was then weighed and separated for verification of the microstructure by scanning electron microscopy (SEM) using a Zeiss EVO MA10 device assisted by SmartSEM software.

Figures $2 \mathrm{~A}$ to $2 \mathrm{D}$ show the thermal images from the surface of the mixture particles of iron ore and coke after microwave application obtained using a thermal camera FLIR Systems AB model T440. It should be noted that the temperature on the surface of the samples is considerably lower than in the interior regions, a fact that can be explained due to specific characteristics of microwave heating, which promotes heating that spreads from the materials core.

Without reaching the final degree of reduction through experiments, the degree of reduction of the samples was then determined based on the dissociation of oxygen bound to the iron atoms, using Equation 1, adapted from a reference ${ }^{39}$ as follows:

$$
R=\frac{4}{7 W_{O}}\left(f_{t}-f_{\text {carbon }}-f_{\text {vol }}\right) W
$$

Where $R$ is the degree of reduction of the samples after the test, $W_{O}$ is the amount of oxygen present in the iron oxides contained in the ore, $f_{t}$ is the percentage of total weight loss of the sample after the test, $f_{\text {carbon }}$ is the carbon weight loss by gasification, $f_{v o l}$ is the weight of volatile matter lost during the test time considered and $W$ is the initial weight 
Table 4. The specific description of the tests performed obtained through the factorial design of experiments using the central composite rotatable design (CCRD).

\begin{tabular}{|c|c|c|c|c|c|c|}
\hline Test & Time (levels) & Power (levels) & Coke (levels) & Time (min) & Power (\%) & Coke $(\% w t)$ \\
\hline 1 & -1 & -1 & -1 & 3 & 30 & 10 \\
\hline 2 & 1 & -1 & -1 & 9 & 30 & 10 \\
\hline 3 & -1 & 1 & -1 & 3 & 70 & 10 \\
\hline 4 & 1 & 1 & -1 & 9 & 70 & 10 \\
\hline 5 & -1 & -1 & 1 & 3 & 30 & 20 \\
\hline 6 & 1 & -1 & 1 & 9 & 30 & 20 \\
\hline 7 & -1 & 1 & 1 & 3 & 70 & 20 \\
\hline 8 & 1 & 1 & 1 & 9 & 70 & 20 \\
\hline 9 & -1.68 & 0 & 0 & 1 & 50 & 15 \\
\hline 10 & 1.68 & 0 & 0 & 11 & 50 & 15 \\
\hline 11 & 0 & -1.68 & 0 & 6 & 10 & 15 \\
\hline 12 & 0 & 1.68 & 0 & 6 & 100 & 15 \\
\hline 13 & 0 & 0 & -1.68 & 6 & 50 & 5 \\
\hline 14 & 0 & 0 & 1.68 & 6 & 50 & 25 \\
\hline 15 & 0 & 0 & 0 & 6 & 50 & 15 \\
\hline 16 & 0 & 0 & 0 & 6 & 50 & 15 \\
\hline 17 & 0 & 0 & 0 & 6 & 50 & 15 \\
\hline 18 & 0 & 0 & 0 & 6 & 50 & 15 \\
\hline 19 & 0 & 0 & 0 & 6 & 50 & 15 \\
\hline 20 & 0 & 0 & 0 & 6 & 50 & 15 \\
\hline
\end{tabular}

of the sample. To estimate the carbon and volatile weight loss during the tests, initially, thermogravimetric tests were performed for the coke fines separately, covering all points of the experimental design and additional points, in order to obtain a profile of weight loss as a function of time reaction and microwave power as shown in Figure 3.

\subsection{Determination of the controlling step of the iron ore reduction rate}

In order to determine the controlling step of the selfreduction process studied in this work, additional points were obtained for the central values of power and amount of coke. Table 5 shows the tests performed.

The reduction of iron ore particles includes a heterogeneous reaction and assuming that the iron ore and coke particles have a spherical geometry and the chemical reaction is the reaction rate-controlling step, the equation of the unreacted core model can be used to describe the reaction kinetics process:

$1-(1-\alpha)^{1 / 3}=k_{C} t$

Where:

$\alpha=$ Reduced fraction of iron ore in the sample;

$k_{C}=$ Kinetic constant of the chemical control mechanism; $t=$ Reaction time.

Likewise, if the diffusion is the controlling step of the reaction kinetics, the following equation represents this mechanism:

$\left[1-3(1-\alpha)^{2 / 3}+2(1-\alpha)\right]=K_{D} t$

Where:

$\alpha=$ Reduced fraction of iron ore in the sample;

$k_{D}=$ Kinetic constant of the diffusional control mechanism;
Table 5. Definition of the tests necessary to obtain the controlling step of the self-reduction phenomenon for the samples.

\begin{tabular}{cccc}
\hline Test & Time $(\mathrm{min})$ & Power $(\%)$ & Coke $(\% \mathrm{wt})$ \\
\hline 1 & 1 & 50 & 15 \\
\hline 2 & 3 & 50 & 15 \\
\hline 3 & 6 & 50 & 15 \\
\hline 4 & 9 & 50 & 15 \\
\hline 5 & 11 & 50 & 15 \\
\hline
\end{tabular}

\section{$t=$ Reaction time.}

According to Equations 2 and 3, when the chemical reaction becomes the kinetics control step, plotting the expression $1-(1-\alpha)^{1 / 3}$ versus the test time will result in line with a $k_{C}$ slope. In the same way, when the process is controlled by diffusion through the solid product layer, plotting the expression $\left[1-3(1-\alpha)^{2 / 3}+2(1-\alpha)\right]$ versus the test time will also result in a line, whose slope is $k_{D}{ }^{40}$.

\section{Results and Discussions}

\subsection{Carbothermal reduction of samples using microwave energy}

Table 6 shows the results of the thermogravimetric tests for the carbothermic reduction of the self-reducing mixtures. It was found that the highest degree of reduction obtained was for the sample containing $20 \%$ weight of coke when tested for 9 minutes at $70 \%$ power $(840 \mathrm{~W})$, reaching values greater than $60 \%$ reduction. Figure 4 shows a pig iron droplet found attached to the bottom of the crucible for the sample 

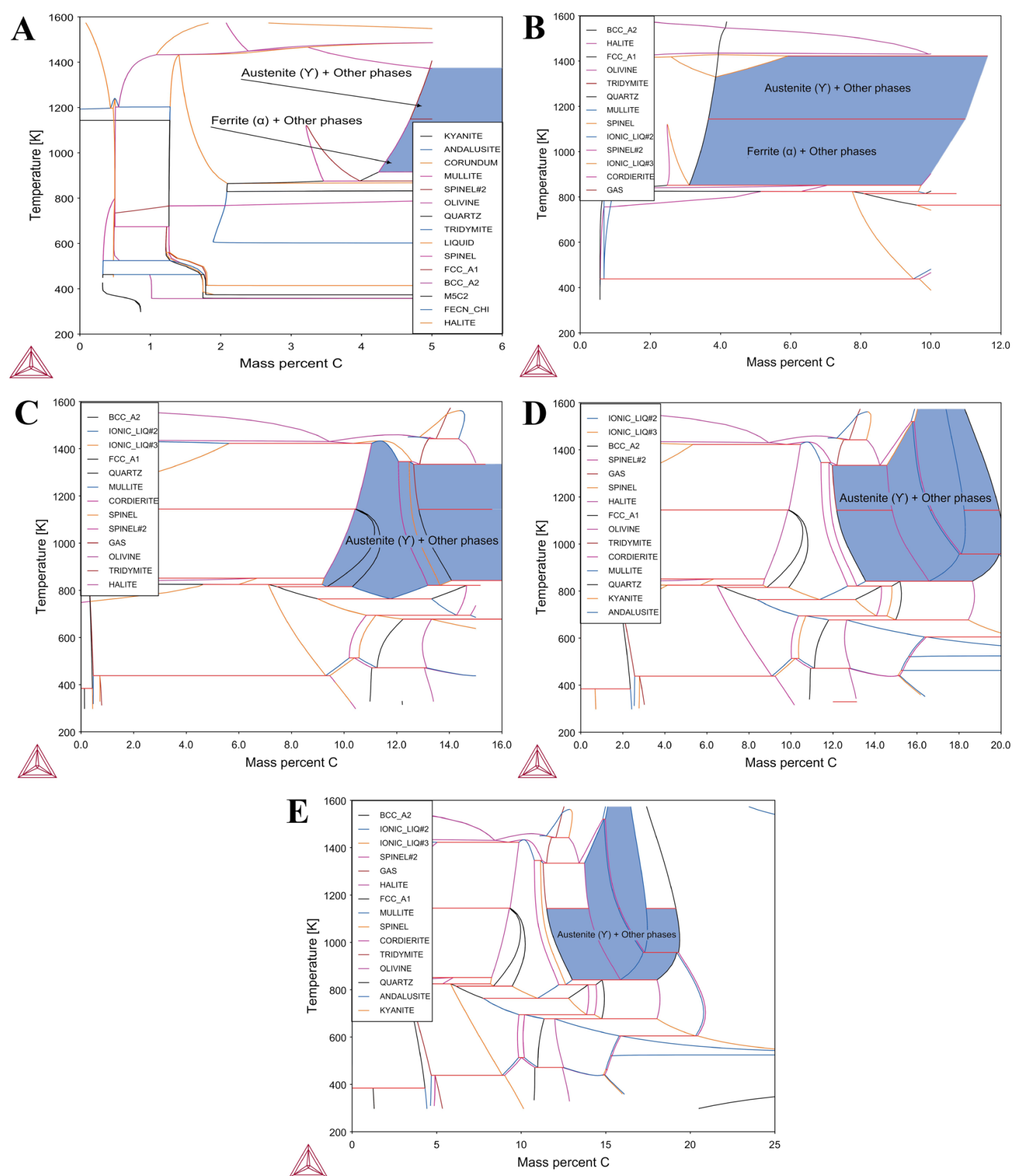

Figure 1. Phase diagrams obtained for self-reducing mixtures containing (a) $5 \%$, (b) $10 \%$, (c) $15 \%$, (d) $20 \%$ and (e) $25 \%$ coke. Calculated

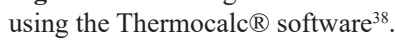

with the greatest degree of reduction after removing the remaining unreacted powder.

In order to obtain a better visualization of the results regarding the influence of the independent variables time and power on the degree of reduction of the samples, response surfaces were obtained that illustrate the relationship between these variables. For this, the results of Table 6 were used applying the distance weighted least squares technique. The results can be seen in Figures 5 and 6, which show, respectively, the response surfaces and contour plots for the effects of time and power, and time and amount of coke in the degree of reduction of the samples after the tests.

Figures $5 \mathrm{~A}$ and $5 \mathrm{~B}$ show the degree of reduction as a function of microwave power applied and the time of contact of the particles with the microwave energy. It was possible to observe that higher values of the degree of reduction were obtained for higher time and power applied values. However, it can be noted that, when considering sections 


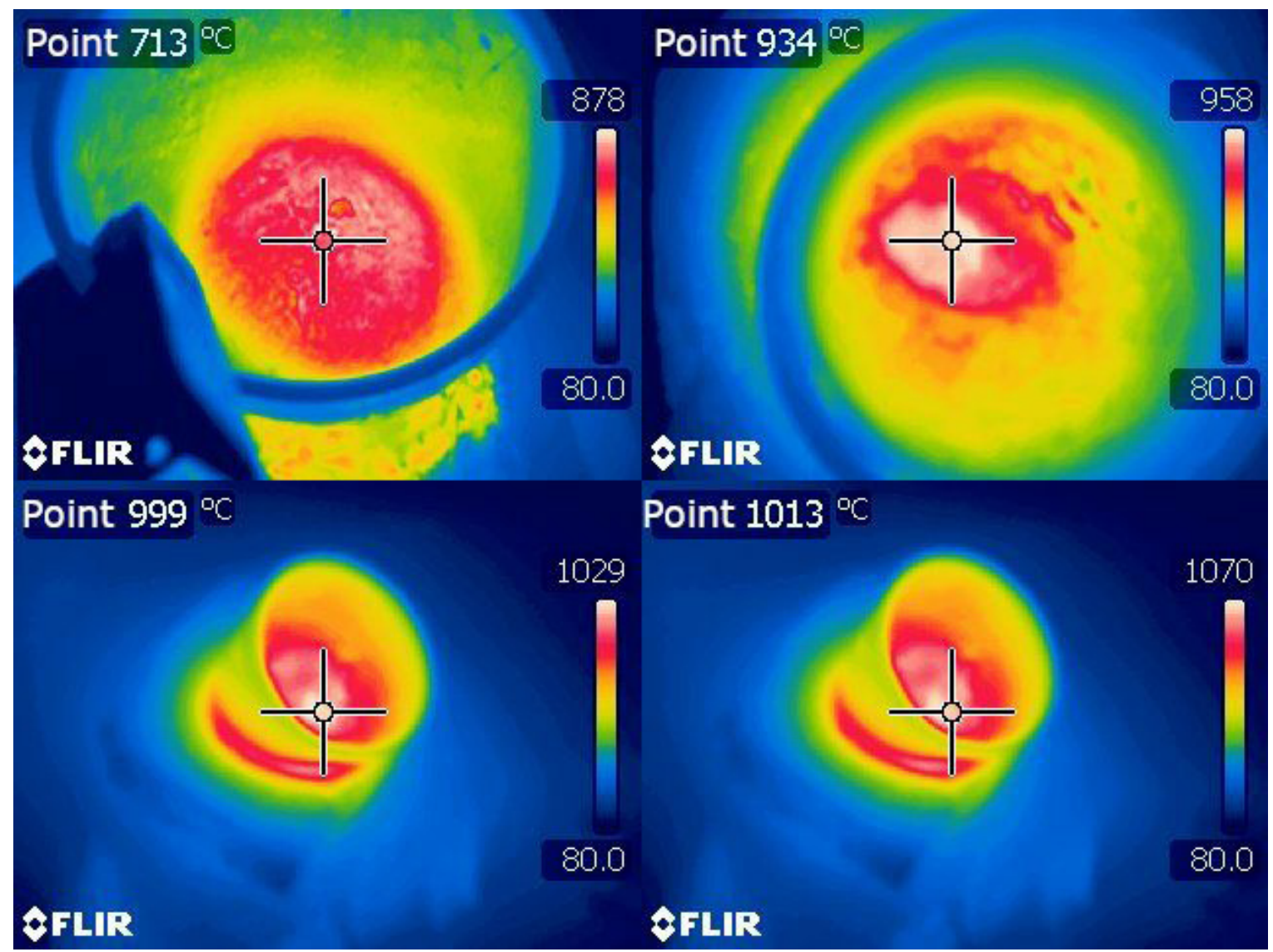

Figure 2. Thermal images of particles from the mixture of iron ore and coke after reaction time under microwave heating obtained using a thermal camera FLIR T440.

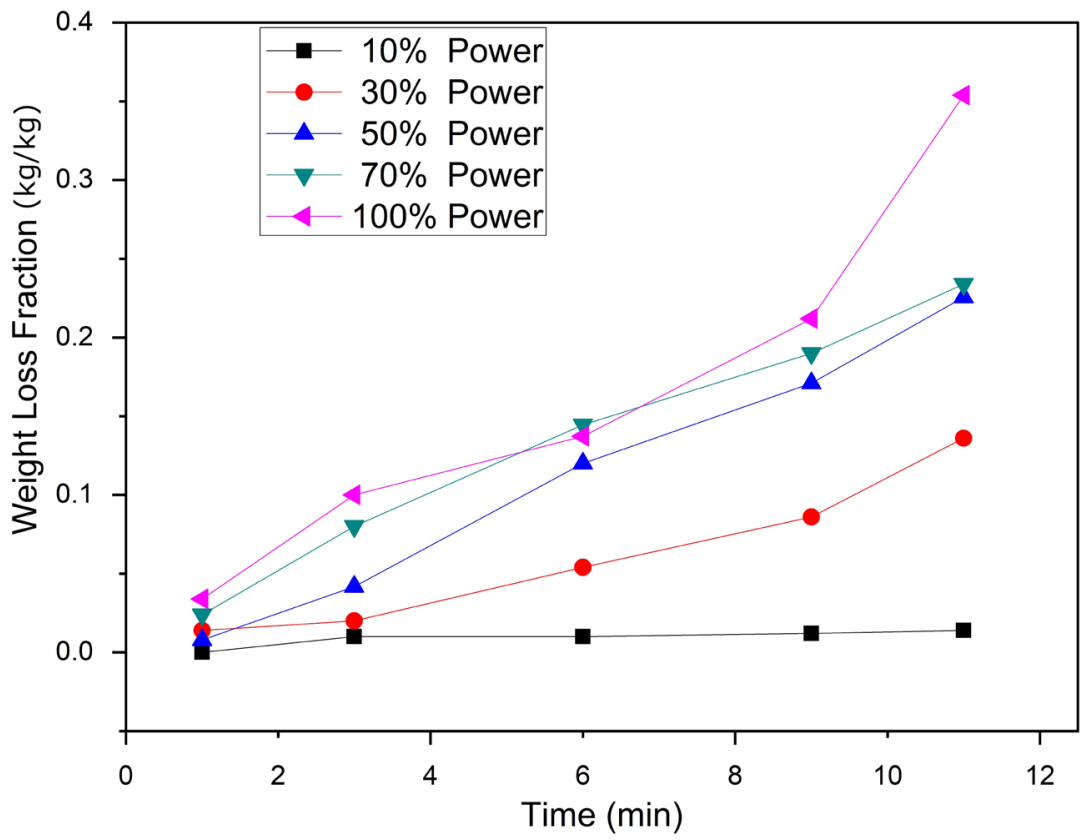

Figure 3. Carbon and volatile weight loss in the coke fines as a function of reaction time and microwave power. 
Table 6. Results of thermogravimetric tests for the carbothermic reduction of self-reducing mixtures.

\begin{tabular}{ccccccc}
\hline \multirow{2}{*}{ Test } & \multicolumn{2}{c}{ Mass $(\mathrm{g})$} & Total Weight & $\begin{array}{c}\text { Oxygen Amount } \\
\text { in Iron Oxides } \\
(\mathrm{g})\end{array}$ & $\begin{array}{c}\text { Carbon } \\
\text { Gasification and } \\
\text { Volatile Loss (\%) }\end{array}$ & $\begin{array}{c}\text { Reduction } \\
\text { Degree }(\%)\end{array}$ \\
\cline { 2 - 3 } & Before Test & After Test & & 2.409 & 0.178 & 2.662 \\
\hline 1 & 10 & 9.87 & 1.3 & 2.409 & 0.765 & 28.783 \\
\hline 3 & 10 & 8.71 & 12.9 & 2.409 & 0.712 & 0.210 \\
\hline 4 & 10 & 9.92 & 0.8 & 2.409 & 1.690 & 37.499 \\
\hline 5 & 10 & 8.25 & 17.5 & 2.142 & 0.356 & 1.719 \\
\hline 6 & 10 & 9.9 & 1.0 & 2.142 & 1.530 & 37.277 \\
\hline 7 & 10 & 8.45 & 15.5 & 2.142 & 1.423 & 26.622 \\
\hline 8 & 10 & 8.86 & 11.4 & 2.142 & 3.380 & 63.027 \\
\hline 9 & 10 & 7.30 & 27.0 & 2.275 & 0.106 & 0.000 \\
\hline 10 & 10 & 10.0 & 0.0 & 2.275 & 3.009 & 48.949 \\
\hline 11 & 10 & 7.75 & 22.5 & 2.275 & 0.133 & 1.172 \\
\hline 12 & 10 & 9.94 & 0.6 & 2.275 & 1.830 & 38.097 \\
\hline 13 & 10 & 8.30 & 17.0 & 2.543 & 0.534 & 18.125 \\
\hline 14 & 10 & 9.14 & 8.6 & 2.008 & 2.668 & 40.792 \\
\hline 15 & 10 & 8.30 & 17.0 & 2.275 & 1.601 & 41.184 \\
\hline 16 & 10 & 8.20 & 18.0 & 2.275 & 1.601 & 37.668 \\
\hline 17 & 10 & 8.34 & 16.6 & 2.275 & 1.601 & 28.627 \\
\hline 18 & 10 & 8.70 & 13.0 & 2.275 & 1.601 & 32.897 \\
\hline 19 & 10 & 8.53 & 14.7 & 2.275 & 1.601 & 34.152 \\
\hline 20 & 10 & 8.48 & 15.2 & 2.275 & 1.601 & 36.915 \\
\hline
\end{tabular}

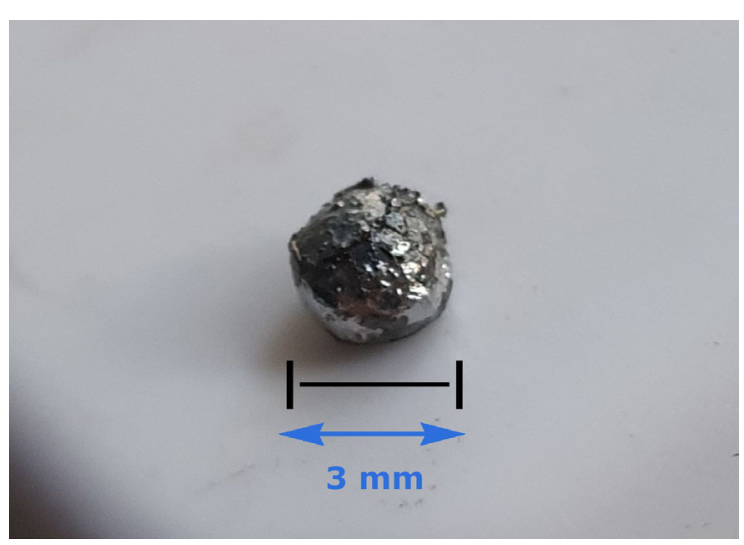

Figure 4. Pig iron droplet obtained from the sample with the highest degree of reduction.

at different levels of reaction time in the graph in Figure 5, the reaction kinetics are maintained at a higher rate between $10 \%$ and $50 \%$ of power ( $120 \mathrm{~W}$ and $600 \mathrm{~W}$, respectively), acquiring a less inclined profile between $50 \%$ and $100 \%$ of power ( $600 \mathrm{~W}$ and $1200 \mathrm{~W}$, respectively). When considering the power sections of the graph, subgraphs of the degree of reduction versus time are obtained. These exhibit a form very similar to those found in several studies ${ }^{2-5}$. Similarly, Figures $6 \mathrm{~A}$ and $6 \mathrm{~B}$ indicated that higher levels of amount of coke up to $25 \%$ wt at any microwave power value applied to the particles favor the process of reduction by steps of hematite contained in the ore.

Such results that demonstrate the efficiency of microwave energy in this process can be confirmed by Haque et al. ${ }^{9}$ who stated that the rapid heating of the ore particles that occurred through the application of microwave energy to ore with a transparent matrix generates thermal stress of sufficient magnitude to create micro-cracks along the grain boundaries of the minerals. This type of micro-cracks has a high potential for improving the efficiency of iron ore reduction processes.

According to Silva ${ }^{41}$, the hematite mineral for being an extremely active mineral when exposed to microwave radiation undergoes expansion in greater volume in relation to the gangue minerals, and the difference caused by this expansion results in the formation of intergranular fractures. Jones et al. ${ }^{16}$, further reinforces that fractures in the ore particles occur throughout the grain boundary between absorbent and transparent species.

Still, according to Omran et al. ${ }^{42}$, in microwave pretreatment processes, intergranular fractures are generated between the gangue (fluorapatite and chamosite) and oolitic hematite. These intergranular fractures improve the release of iron ore and the removal of phosphorus and gangue minerals from oolitic hematite, which may favor the reduction mechanism.

Through the data obtained in the tests of reduction kinetics, a statistical plot of the importance of the independent variables in the results observed for the degree of reduction was also constructed, indicating a level of dependence on this dependent variable. This graph is shown in Figure 7 and indicates the test time as the main independent variable in the reduction process, which means that variations in this variable generate the greatest changes in the degree of reduction, followed by the power and the coke content in the mixture. 

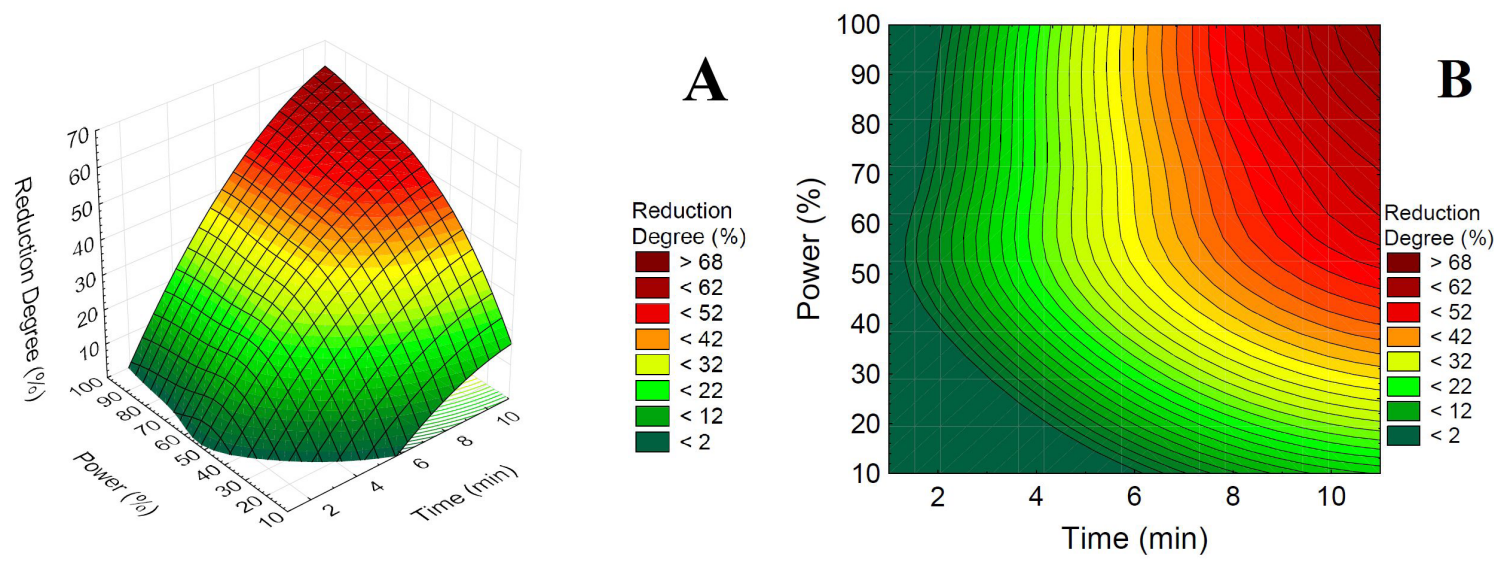

Figure 5. Response surface (A) and contour plot (B) for the degree of reduction of iron ore as a function of microwave power applied and time of contact of the particles with microwave energy.
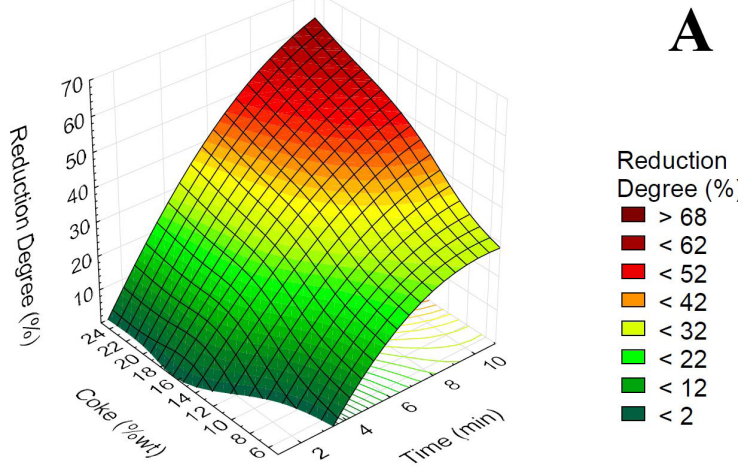

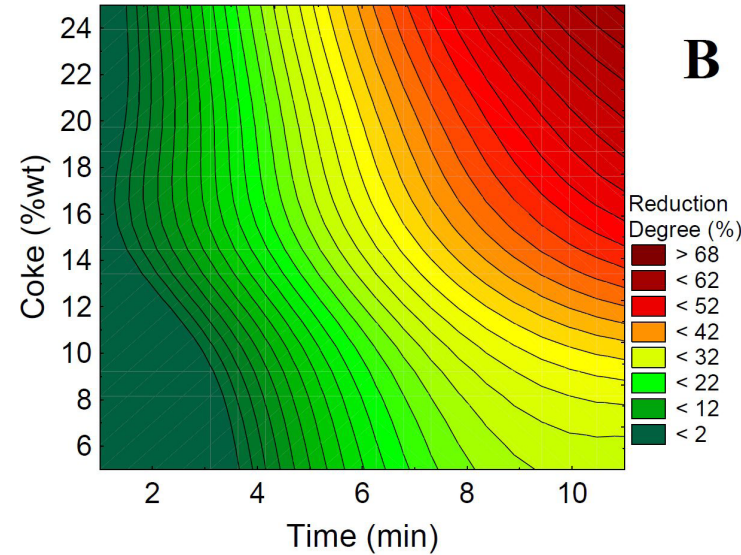

Figure 6. Response surface (A) and contour plot (B) for the degree of reduction of iron ore as a function of the amount of coke and time of contact of the particles with microwave energy.

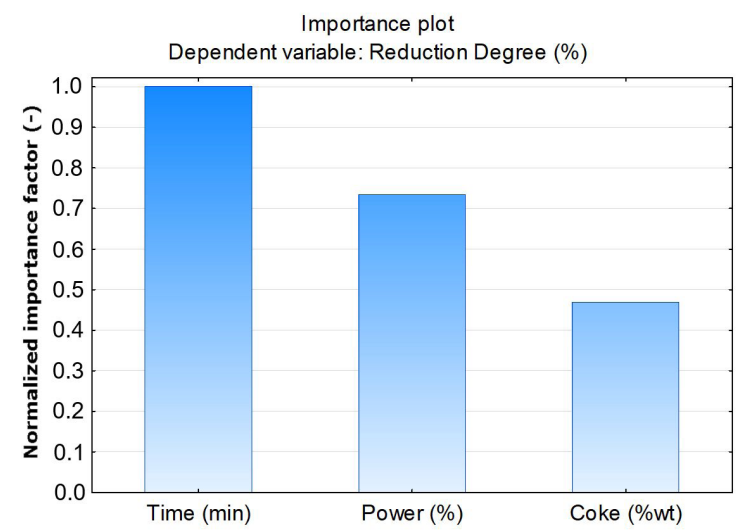

Figure 7. Influence of the independent variables time, power, and coke content on the dependent variable, degree of reduction.

\subsection{SEM analysis of the reduced samples}

Figures 8 and 9A, B, C, and D show the images of the microstructures obtained through scanning electron microscopy (SEM) for the samples that attained considerable degrees of reduction after contact with the microwave energy.

Figure 8 shows the surface microstructure of a porous region composed of pig iron formed inside the powder sample inserted in the crucible, similar to the iron droplet in Figure 4, showing a dense pig iron structure with dispersed porosity as indicated. This result is very similar to the descriptions made by Standish and Pramusanto ${ }^{28}$ who conducted similar experiments and can only be obtained when temperatures above the eutectic of the iron-carbon system $\left(1147^{\circ} \mathrm{C}\right)$ are reached.

Figures 9A and 9B show regions of the powder sample where droplets like the one in Figure 4 were not formed after the reduction test. In Figure 9A, through the images generated 
by scanning electron microscopy in magnifications of the order of 500x to 2500x, the formation of an elongated and compact filamentary structure is observed, whose filaments can be better observed by the indication of Figure 9B, in higher magnification. This microstructure can be observed in several regions of the sample.

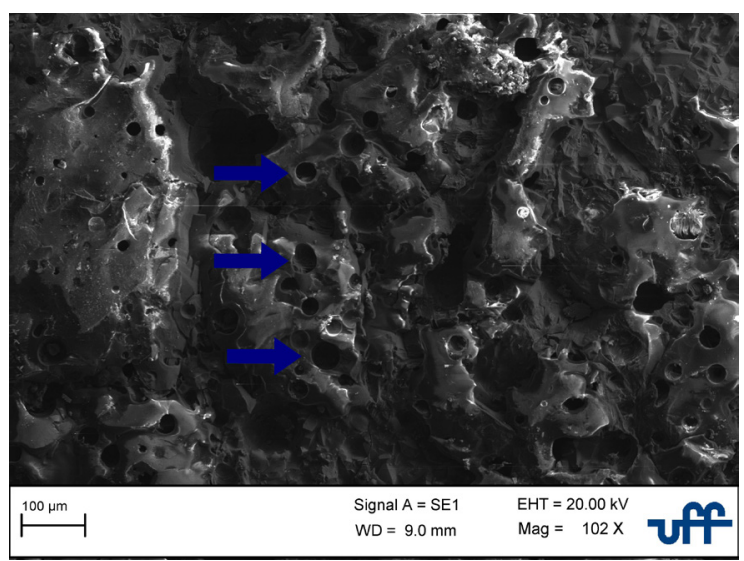

Figure 8. Micrograph obtained by scanning electron microscopy (SEM) of a pig iron droplet surface found inside the powder sample after reduction test. Arrows indicate porosity.
According to Takano and Mourão ${ }^{43}$ this microstructure called whiskers is formed by metallic iron resulting from the final stage of reduction $\mathrm{FeO} \rightarrow \mathrm{Fe}$ at temperatures between $800^{\circ} \mathrm{C}$ and $1150^{\circ} \mathrm{C}$ and is less likely to happen for mixtures containing coke in which there are no considerable levels of basic oxides. This phenomenon is, in fact, observed since the formed whiskers exhibit short length when compared to the case that favors their formation as described.

It was also found a microstructure formed by spherical particles, represented in Figure 9C as light-colored globules, which suggests the melting of one of the phases present initially or formed later. However, considering the initial composition of iron ore, most phases are present in small quantities or have high melting points (above $1377^{\circ} \mathrm{C}$ for chemical species containing iron and as high as $1710^{\circ} \mathrm{C}$ and $1750^{\circ} \mathrm{C}$ for Quartz and Kaolinite, respectively). When considering the relatively high content of $\mathrm{SiO}_{2}$ contained in iron ore, one can assume the occurrence of the formation of Fayalite $\left(\mathrm{Fe}_{2} \mathrm{SiO}_{4}\right)$ and its subsequent melting at temperatures above $1217^{\circ} \mathrm{C}^{44}$.

Other images obtained (Figure 9D) show a mixed microstructure among those previously discussed, composed of pig iron whiskers and spherical particles from the melting of other phases.

In view of these results, it can be considered that temperatures of at least $1200^{\circ} \mathrm{C}$ were reached inside the

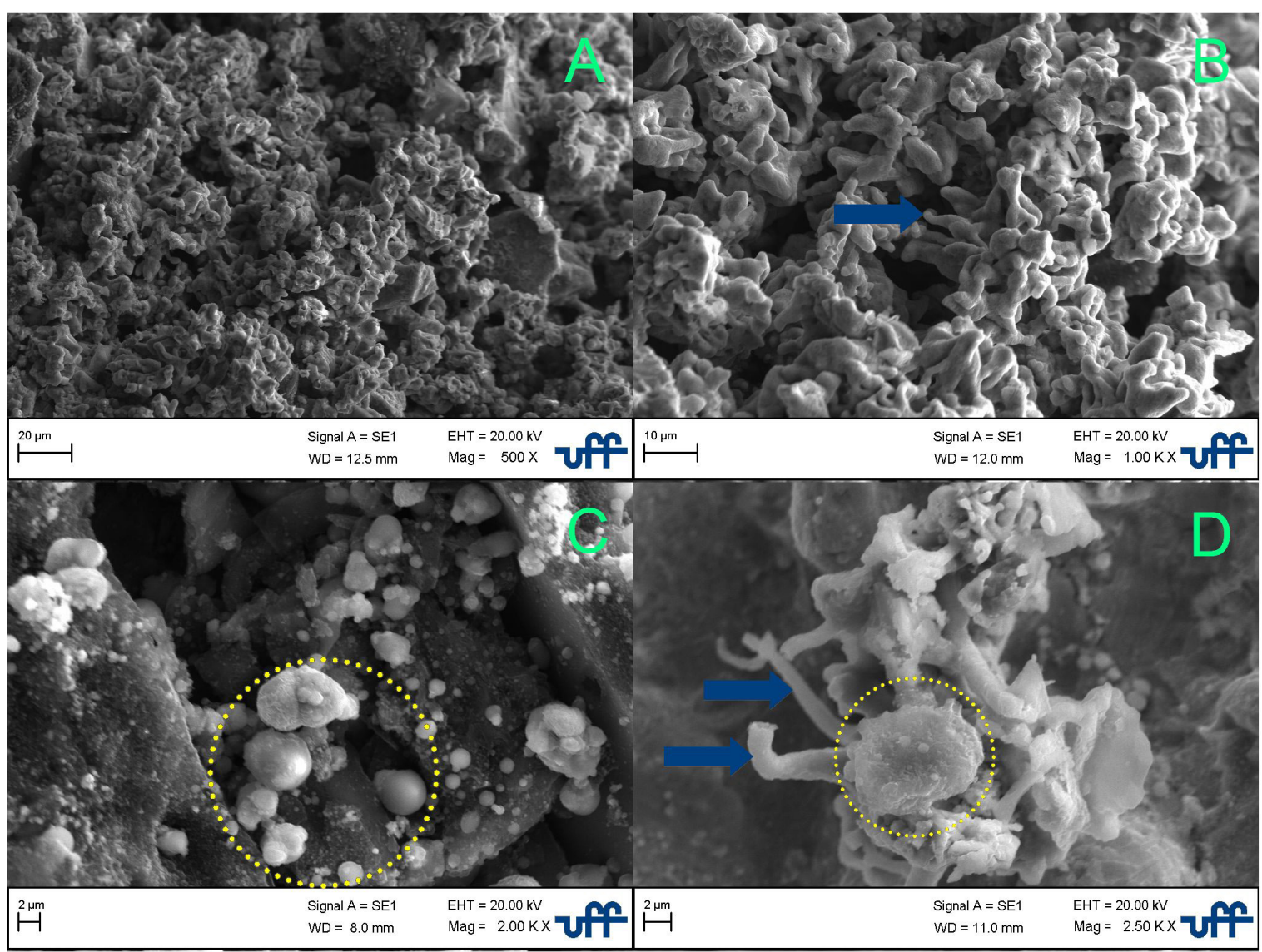

Figure 9. Microstructures observed through scanning electron microscopy (SEM) for samples that obtained considerable degrees of reduction after contact with microwave energy. Arrows indicate whiskers and circles indicate melted phases. 
samples that, during the kinetic tests, obtained the highest degrees of reduction (longest reaction times, power levels, and coke content).

In line with what was previously reported, the work carried out by Roy and Agrawal ${ }^{45}$ indicated that the interaction of the magnetic field with some materials contributes a lot to the heating rate, which could lead to the occurrence of localized temperature gradients inside the samples during the test ${ }^{4}$ justifying the presence of pig iron in different morphologies.

According to Haque et al. ${ }^{9}$ the maximum temperature reached occurs due to the increase in the magnetic saturation and the remaining magnetization of the iron ore samples. When the frequency of $2450 \mathrm{MHz}$ is used, the alignment of the molecules and their return to the state of disorder occurs $4,9 \times 10^{9}$ times per second, which results in a quick and efficient heating. However, the heating due to this process depends on the relaxation time of the sample, being defined as the time necessary to totally order and disorder $63 \%$ of the sample ${ }^{46}$. Microwave energy then provides a possible mechanism to induce the rupture between valuable minerals in the ore and gangue. This fact can be explained due to the difference in the absorption of microwave energy and the thermal differences given by the expansion coefficients between the various mineral phases in the iron ore particles.

\subsection{Analysis of the controlling step of the carbothermic reduction process of samples submitted to microwave energy}

Table 7 shows the results obtained for the tests performed with the objective of determining the controlling step of the microwave self-reduction reaction.

Figure 10 presents the evaluation of the chemical and diffusional control steps based on the results from the reduction tests.

The controlling step of the reaction rate was evaluated in samples of $10 \mathrm{~g}$ of self-reducing mixture with an average particle size less than $53 \mu \mathrm{m}$ in different residence times under microwaves with power levels of $50 \%$ of the total emission capacity. It was possible to observe that for the reduction of iron oxides using microwave energy, there is a tendency towards the chemical control stage indicated by the better correlation results obtained for this model, as shown in Figure $10\left(R^{2} \cong 0.95\right)$, and therefore the contact surface between the iron ore and coke particles as well as the carbon gasification of the coke contained in the samples becomes an important factor for the kinetics of the reduction process using microwave energy as a heating source. Poor correlation results were observed for the diffusional model ( $R^{2} \cong 0.78$ ), further supporting the previous results.

In this way, it is possible to affirm that the attained reduction degree is also due to the generation of fractures along the particles since such a mechanism increase the contact surface between coke and iron ore particles. This contact is especially relevant in the self-reduction processes, where the contact between the particles and the absorbed energy provides the formation of internal reducing gases ${ }^{47}$.

These mechanisms are in agreement with that observed by Walkiewicz et al. ${ }^{48}$ who affirm that the rapid heating of the ore occurs due to the presence of the high energy of the microwaves, being absorbed by minerals that contain high content of iron. On the other hand, the matrix with a greater amount of gangue with low absorption of microwave energy can generate large thermal gradients that allow tension to occur in the particle, causing thermal stresses that causes microfractures along the boundaries of mineral grains.

In agreement with the previous statement, applying a magnetic field to a diamagnetic substance (with zero magnetic moments in the absence of a field) is responsible for the induction of a magnetic moment whose direction is opposite to that of the applied external field. This is an effect exactly opposite to that produced by paramagnetism, where the permanent magnetic dipole tends to align itself in the same direction as the external field.

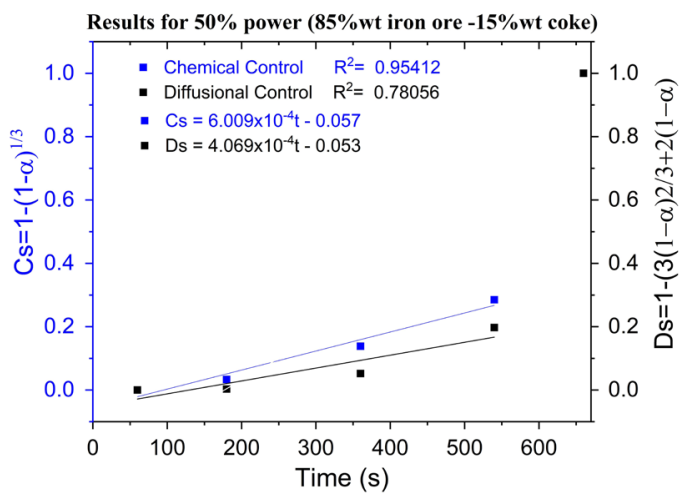

Figure 10. Evaluation of the chemical and diffusional control step for the reduction tests by microwave heating.

Table 7. Results of thermogravimetric tests to determine the controlling step of the reaction kinetics.

\begin{tabular}{|c|c|c|c|c|c|c|}
\hline \multirow{2}{*}{ Test } & \multicolumn{2}{|c|}{ Mass (g) } & \multirow{2}{*}{$\begin{array}{c}\text { Total Weight } \\
\text { Loss }(\%)\end{array}$} & \multirow{2}{*}{$\begin{array}{c}\text { Oxygen Amount } \\
\text { in Iron Oxides } \\
(\mathrm{g})\end{array}$} & \multirow{2}{*}{$\begin{array}{c}\text { Carbon } \\
\text { Gasification and } \\
\text { Volatile Loss }(\%) \\
\end{array}$} & \multirow{2}{*}{$\begin{array}{c}\text { Reduction } \\
\text { Degree (\%) }\end{array}$} \\
\hline & Before Test & After Test & & & & \\
\hline 1 & 10 & 10.00 & 0.0 & 2.275 & 0.106 & 0.000 \\
\hline 2 & 10 & 9.43 & 5.7 & 2.275 & 0.557 & 12.916 \\
\hline 3 & 10 & 8.44 & 15.6 & 2.275 & 1.601 & 35.241 \\
\hline 4 & 10 & 8.31 & 16.9 & 2.275 & 2.281 & 36.714 \\
\hline 5 & 10 & 7.75 & 22.5 & 2.275 & 3.009 & 48.949 \\
\hline
\end{tabular}


From a chemical point of view and according to Nascimento et al. ${ }^{49}$ for processes below $1100^{\circ} \mathrm{C}$, Boudouard's reaction is much slower than the reduction of wustite to iron. During this reduction step, the iron nucleates and grows in conditions very close to those of equilibrium in the $\mathrm{Fe}-\mathrm{C}-\mathrm{O}$ system. Therefore, the presence of whiskers indicates that the Boudouard reaction was slower than the diffusion of iron cations in the $\mathrm{FeO}$ structure, with gasification being the controlling chemical step of the self-reduction process ${ }^{50}$.

Thus, it can be observed that microwave energy, through the formation of fractures inside the iron ore particles, increases the contact between the iron ore and coke particles, thus enabling higher values of iron oxides reduction in the iron ore particles. However, the temperatures reached inside the sample made the system highly dependent on the chemical step, with most of the pig iron being obtained in the form of whiskers, as noted in the previous section.

\section{Conclusion}

In order to evaluate the carbothermic reduction profile of the iron oxides content in iron ore/coke self-reducing powder mixtures, as well as the reduction rate-controlling step by heating using microwave energy, an evaluation of the reduction degree, as well as the chemical and diffusional control steps in samples during the reduction step were carried out.

High levels of metalization were obtained in relatively short times. Higher degrees of reduction occurred for higher values of coke and higher levels of power and contact times of the particles with microwave energy, with the test time being the main factor for the reduction process, followed by power and coke content in the mixture.

The correlation results for the controlling step of reaction rate showed that the degree of reduction of iron oxides in the iron ore particles using microwave energy follows the chemical control kinetics, controlled by the superficial interaction between coke and iron ore particles as well as coke gasification reactions.

Through images obtained by scanning electron microscopy that indicate the occurrence of melting, it is possible to conjecture the attainment of temperatures of at least $1200^{\circ} \mathrm{C}$ inside the samples that obtained greater degrees of reduction, with temperatures above $1000^{\circ} \mathrm{C}$ measured on the surface. Pig iron was obtained both in the form of whiskers and metallic droplets.

\section{Acknowledgments}

The authors thank the funding agencies: Coordination of Improvement of Higher Education Personnel (CAPES) and National Council for Scientific and Technological Development (CNPq), Ministry of Science and Technology. They also thank the Program in Metallurgical Engineering of the Federal Fluminense University for the scientific and technical support.

\section{References}

1. Ariyama T, Sato M, Nouchi T, Takahashi K. Evolution of blast furnace process toward reductant flexibility and carbon dioxide mitigation in steel works. ISIJ Int. 2016;56:1681-96. http:// dx.doi.org/10.2355/isijinternational.ISIJINT-2016-210.

2. Mouräo MB, Carvalho IP Jr, Takano C. Carbothermic reduction by microwave heating. ISIJ Int. 2001;41:S27-30. http://dx.doi. org/10.2355/isijinternational.41.Suppl_S27.

3. Ishizaki K, Nagata K, Hayashi T. Production of pig iron from magnetite ore-coal composite pellets by microwave heating. ISIJ Int. 2006;46:1403-9. http://dx.doi.org/10.2355/ isijinternational.46.1403.

4. Ishizaki K, Nagata K, Hayashi T. Localized heating and reduction of magnetite ore with coal in composite pellets using microwave irradiation. ISIJ Int. 2007;47:817-22. http://dx.doi. org/10.2355/isijinternational.47.817.

5. Takayama S, Link G, Thumm M, Matsubara A, Sato M, Sano S. Reduction of magnetite in air by use of microwave heating. In: 2007 IEEE International Vacuum Electronics Conference; 2007; Kitakyushu, Japan. Proceedings. USA: IEEE; 2007. p. 1-2. http://dx.doi.org/10.1109/IVELEC.2007.4283402.

6. Ghoreshy M, Pickles CA. Microwave processing of electric arc furnace dust. In: 52nd Electric Furnace Conference, ISS-AIME; 1994; Nashville. Proceedings. Nova York: American Institute of Mining, Metallurgical \& Petroleum Engineers, Inc.; 1994. p. $187-96$

7. Li K, Jiang Q, Chen J, Peng J, Li X, Koppala S, et al. The controlled preparation and stability mechanism of partially stabilized zirconia by microwave intensification. Ceram Int. 2020;46:7523-30. http://dx.doi.org/10.1016/j.ceramint.2019.11.251.

8. Li K, Chen J, Peng J, Koppala S, Omran M, Chen G. One-step preparation of $\mathrm{CaO}$-doped partially stabilized zirconia from fused zirconia. Ceram Int. 2020;46:6484-90. http://dx.doi. org/10.1016/j.ceramint.2019.11.129.

9. Haque KE. Microwave energy for mineral treatment processes: a brief review. Int J Miner Process. 1999;57:1-24. http://dx.doi. org/10.1016/S0301-7516(99)00009-5.

10. Li K, Chen J, Peng J, Ruan R, Srinivasakannan C, Chen G. Pilot-scale study on enhanced carbothermal reduction of lowgrade pyrolusite using microwave heating. Powder Technol. 2020;360:846-54. http://dx.doi.org/10.1016/j.powtec.2019.11.015.

11. Li K, Chen J, Peng J, Omran M, Chen G. Efficient improvement for dissociation behavior and thermal decomposition of manganese ore by microwave calcination. J Clean Prod. 2020;260:121074. http://dx.doi.org/10.1016/j.jclepro.2020.121074.

12. Li K, Chen J, Peng J, Ruan R, Omran M, Chen G. Dielectric properties and thermal behavior of electrolytic manganese anode mud in microwave field. J Hazard Mater. 2020;384:121227. http://dx.doi.org/10.1016/j.jhazmat.2019.121227.

13. Li K, Chen J, Chen G, Peng J, Ruan R, Srinivasakannan C. Microwave dielectric properties and thermochemical characteristics of the mixtures of walnut shell and manganese ore. Bioresour Technol. 2019;286:121381. http://dx.doi. org/10.1016/j.biortech.2019.121381.

14. Li K, Jiang Q, Gao L, Chen J, Peng J, Koppala S, et al. Investigations on the microwave absorption properties and thermal behavior of vanadium slag: improvement in microwave oxidation roasting for recycling vanadium and chromium. J Hazard Mater. 2020;395:122698. http://dx.doi.org/10.1016/j. jhazmat.2020.122698.

15. Hartlieb P, Toifl M, Kuchar F, Meisels R, Antretter T. Thermophysical properties of selected hard rocks and their relation to microwave-assisted comminution. Miner Eng. 2016;91:34-41. http://dx.doi.org/10.1016/j.mineng.2015.11.008.

16. Jones DA, Kingman SW, Whittles DN, Lowndes IS. Understanding microwave assisted breakage. Miner Eng. 2005;18:659-69. http://dx.doi.org/10.1016/j.mineng.2004.10.011.

17. Ali AY, Bradshaw SM. Confined particle bed breakage of microwave treated and untreated ores. Miner Eng. 2011;24:162530. http://dx.doi.org/10.1016/j.mineng.2011.08.020. 
18. da Siva LM, Nascimento M, de Oliveira EM, de Queiroz AV, Fernandes MT, de Castro JA. Evaluation of the diffusional coefficient in the acid baking process using microwave energy to reduce phosphorus content in iron ore particles. Miner Eng. 2020;157:106541. http://dx.doi.org/10.1016/j.mineng.2020.106541.

19. da Silva LM, Nascimento M, de Oliveira EM, de Queiroz AV, Fernandes MT, de Castro JA. Evaluation of the acid baking technique to decrease the phosphorus content of the iron ore. Mater Res. 2019;22(4):e20190249. http://dx.doi. org/10.1590/1980-5373-MR-2019-0249.

20. da Silva LM, Nascimento M, de Oliveira EM, de Queiroz AV, Fernandes MT, de Castro JA. Evaluation of the influence of particle size in the acid baking process for the reduction of phosphorus content in iron ore. Mater Res. 2020;23(6):e20200333. http://dx.doi.org/10.1590/1980-5373-MR-2020-0333.

21. Kashimura K, Nagata K, Sato M. Concept of furnace for metal refining by microwave heating - a design of microwave smelting furnace with Low $\mathrm{CO}_{2}$ emission- Mater Trans. 2010;51(10):1847-53. http://dx.doi.org/10.2320/matertrans. M2010026.

22. Hara K, Hayashi M, Sato M, Nagata K. Continuous pig iron making by microwave heating with $12.5 \mathrm{~kW}$ at $2.45 \mathrm{GHz}$. J Microw Power Electromagn Energy. 2011;45:137-47. http:// dx.doi.org/10.1080/08327823.2011.11689808.

23. Cho S, Lee J. Metal recovery from stainless steel mill scale by microwave heating. Met Mater Int. 2008;14:193-6. http:// dx.doi.org/10.3365/met.mat.2008.04.193.

24. Kuroki T, Uchida Y, Takizawa H, Morita K. Effects of 28 $\mathrm{GHz} / 2.45 \mathrm{GHz}$ microwave irradiation on the crystallization of blast furnace slag. ISIJ Int. 2007;47:592-5. http://dx.doi. org/10.2355/isijinternational.47.592.

25. Tae S-J, Tanaka T, Morita K. Effect of Microwave Irradiation on Hydrothermal Treatment of Blast Furnace Slag. ISIJ Int. 2009;49:1259-64. http://dx.doi.org/10.2355/isijinternational.49.1259.

26. Nagata K, Kojima R, Murakami T, Susa M, Fukuyama H. Mechanisms of pig-iron making from magnetite ore pellets containing coal at low temperature. ISIJ Int. 2001;41:1316-23. http://dx.doi.org/10.2355/isijinternational.41.1316.

27. Sawa Y, Yamamoto T, Takeda K, Itaya H. New coal-based process to produce high quality DRI for the EAF. ISIJ Int. 2001;41:S17-21. http://dx.doi.org/10.2355/isijinternational.41. Suppl_S17.

28. Standish N, Pramusanto. Reduction of microwave irradiated iron ore particles in CO. ISIJ Int. 1991;31:11-6. http://dx.doi. org/10.2355/isijinternational.31.11

29. Standish N, Huang W. Microwave application in carbothermic reduction of iron ores. ISIJ Int. 1991;31:241-5. http://dx.doi. org/10.2355/isijinternational.31.241.

30. Zhong S, Geotzman HE, Bleifuss RL. Reduction of iron ore with coal by microwave heating. Mining Metall Explor. 1996;13:174-8. http://dx.doi.org/10.1007/BF03402742.

31. Li K, Jiang Q, Chen G, Gao L, Peng J, Chen Q, et al. Kinetics characteristics and microwave reduction behavior of walnut shell-pyrolusite blends. Bioresour Technol. 2021;319:124172. http://dx.doi.org/10.1016/j.biortech.2020.124172.

32. Li K, Chen G, Chen J, Peng J, Ruan R, Srinivasakannan C. Microwave pyrolysis of walnut shell for reduction process of low-grade pyrolusite. Bioresour Technol. 2019;291:121838. http://dx.doi.org/10.1016/j.biortech.2019.121838.

33. Li K, Chen G, Li X, Peng J, Ruan R, Omran M, et al. Hightemperature dielectric properties and pyrolysis reduction characteristics of different biomass-pyrolusite mixtures in microwave field. Bioresour Technol. 2019;294:122217. http:// dx.doi.org/10.1016/j.biortech.2019.122217.

34. Nishioka K, Taniguchi T, Ueki Y, Ohno K, Maeda T, Shimizu $\mathrm{M}$. Gasification and reduction behavior of plastics and iron ore mixtures by microwave heating. ISIJ Int. 2007;47:602-7. http://dx.doi.org/10.2355/isijinternational.47.602.

35. Ghosh D, Roy AK, Ghosh A. Reduction of ferric oxide pellets with methane. T Iron Steel I Jpn. 1986;26:186-93. http://dx.doi. org/10.2355/isijinternational1966.26.186.

36. ASTM International. ASTM D3172-13(2021)e1. Practice for Proximate Analysis of Coal and Coke. West Conshohocken, PA: ASTM International; 2021. http://dx.doi.org/10.1520/ D3172-13R21E01.

37. Dukino R. Phosphorus in hamersley range iron ore: BHP Internal Report. USA: BHP; 1997.

38. Andersson J-O, Helander T, Höglund L, Shi P, Sundman B. Thermo-Calc \& DICTRA, computational tools for materials science. Calphad. 2002;26:273-312. http://dx.doi.org/10.1016/ S0364-5916(02)00037-8.

39. Liu Z, Bi X, Gao Z, Liu W. Carbothermal reduction of iron ore in its concentrate-agricultural waste pellets. Adv Mater Sci Eng. 2018;2018:e2138268. http://dx.doi.org/10.1155/2018/2138268.

40. Levenspiel O. Chemical reaction engineering. New York: Wiley; 1999.

41. Silva LM. Avaliação da Rota Bio - termo - hidrometalúrgica para redução do teor de fósforo no minério de ferro [tese]. Volta Redonda: Universidade Federal Fluminense; 2015.

42. Omran M, Fabritius T, Elmahdy AM, Abdel-Khalek NA, ElAref M, Elmanawi AE-H. Effect of microwave pre-treatment on the magnetic properties of iron ore and its implications on magnetic separation. Separ Purif Tech. 2014;136:223-32. http:// dx.doi.org/10.1016/j.seppur.2014.09.011.

43. Takano C, Mourão MB. Self-reducing pellets for ironmaking: mechanical Behavior. Miner Process Extr Metall Rev. 2003;24:233-52. http://dx.doi.org/10.1080/714856823.

44. Aguilar JA, Gomez I. Microwaves applied to carbothermic reduction of iron ore pellets. J Microw Power Electromagn Energy. 1997;32:67-73. http://dx.doi.org/10.1080/08327823. 1997.11688325.

45. Peelamedu RD, Roy R, Agrawal D. Anisothermal reaction synthesis of garnets, ferrites, and spinels in microwave field. Mater Res Bull. 2001;36:2723-39. http://dx.doi.org/10.1016/ S0025-5408(01)00743-7.

46. Krug FJ. Métodos de decomposição de amostras. In: V Workshop sobre Preparo de Amostras; 2004; São Paulo. Anais. São Paulo: Instituto de Pesquisas Tecnológicas do Estado de São Paulo; 2004.

47. Takano C, Zambrano A, Braga R, Mourao MB, Narita CY, de Castro JA. Self-reduction process for ferroalloys. In: Sustainable Industrial Processing Summit - Flogen Star Outreach; 2016; Hainan-Island, China. Proceedings. Canadá: FLOGEN Stars Outreach; 2016. vol. 6, p. 178-93.

48. Walkiewicz JW, Kazonich G, McGill SL. Microwave heating characteristics of selected minerals and compounds. Miner Metall Process. 1988;5(1):39-42. http://dx.doi.org/10.1007/ BF03449501.

49. Nascimento RC, Mourão MB, Capocchi JDT. Microstructures of self-reducing pellets bearing iron ore and carbon. ISIJ Int. 1997;37:1050-6. http://dx.doi.org/10.2355/isijinternational.37.1050.

50. Araújo GM. Estudo da cinética de redução dos óxidos de ferro com a proposição de um novo aglomerado autorredutor [tese]. Volta Redonda: Universidade Federal Fluminense; 2013. 